\title{
No Detectable Alteration of Inorganic Allogeneic Bone Matrix Colonizing Mesenchymal Cells: A Step Towards Personalized Bone Grafts
}

\author{
Roger Erivan 1,2, Nicolas Samper ${ }^{3}$, Guillaume Villatte' ${ }^{1}$ Stéphane Boisgard' ${ }^{1}$ Stéphane Descamps ${ }^{1}$, Marc Berger ${ }^{4}$ \\ 'Université Clermont Auvergne, CHU Clermont-Ferrand, CNRS, SIGMA Clermont, ICCF, Clermont-Ferrand; \\ ${ }^{2}$ Department of Orthopedic and Trauma Surgery, Hôpital Gabriel Montpied, CHU de Clermont Ferrand, Clermont-Ferrand; \\ ${ }^{3}$ Université Clermont Auvergne, CHU Clermont-Ferrand, Clermont, Clermont-Ferrand; \\ ${ }^{4}$ Université Clermont Auvergne, CHU Clermont-Ferrand, GECOM, CRB Auvergne, Clermont-Ferrand, France
}

\author{
Corresponding author \\ Roger Erivan \\ Department of Orthopedic and Trauma \\ Surgery, Hôpital Gabriel Montpied, CHU de \\ Clermont Ferrand, BP 69, 63003 Clermont- \\ Ferrand, France \\ Tel: +33-4-73-751-535 \\ Fax: +33-4-73-751-536 \\ E-mail: rerivan@chu-clermontferrand.fr
}

Received: March 6, 2021

Revised: March 19, 2021

Accepted: March 22, 2021
Background: During major bone substance loss, secured allogeneic bone matrix (ABM) is normally utilized for bone repair. Here, we propose a method to colonize ABM using autologous mesenchymal cells (MCs) to improve their integration. Moreover, in this study, the consequences of in vitro colonization on MCs have been evaluated. Methods: After in vitro propagation of MCs, their proliferation kinetics on ABM pre-coated with gelatin, fibronectin, collagen IV and human serum (HS) was monitored, and they were compared with cells cultured without ABM for 8 weeks. The effect of ABM on cell phenotype was also assessed. Lastly, the ability of ABM-colonizing MCs to perform hematopoiesis, a function normally preserved in selected culture conditions, and their differentiation towards osteoblastic lineage were evaluated. Results: MC and colony-forming unitfibroblast proliferated 930- and 590-fold, respectively. The proliferation rate of the expanded MCs was higher, forming a 3-dimensional structure in all ABMs. Pre-coating with $\mathrm{HS}$ was the most efficient treatment of $A B M s$ to increase the initial adherence of $M C s$, and it partly explains the reason for the higher propagation of MCs. Flow cytometry analyses revealed subtle alterations in ABM-colonizing cells; however, the ability of MCs to maintain long-term culture initiating cells proliferation and differentiate into osteoblastic lineage was preserved. Conclusions: In this study, the in vitro biocompatibility of bone marrow (BM) MCs with ABMs, the role of HS in scaffold coating, and the possibility of initially using a small BM sample for this approach were demonstrated.

Key Words: Biocompatibility · Bone allograft · Mesenchymal progenitor cell

\section{INTRODUCTION}

The use of allogenic human grafts harvested from femoral heads during hip

Copyright $@ 2021$ The Korean Society for Bone and Mineral Research

This is an Open Access article distributed under the terms of the Creative Commons Attribution Non-Commercial License (https://creativecommons.org/licenses/by-nc/4.0/) which permits unrestricted non-commercial use, distribution, and reproduction in any medium, provided the original work is properly cited.

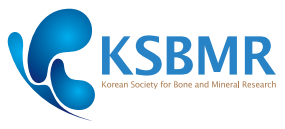
prosthetic surgery or from a cadaveric donor are common,[1-3] it is a valuable option because of its biophysical properties, micro- and macro-architecture. However, the procedure used to make the grafts safe impairs the osteoinductive capacity of the bone structure and, as already reported, integration with surrounding tissue was limited and the consolidation process slow compared to autograft.[4]

The integration of inorganic bone matrix is related to the local environment and particularly to there being sufficient numbers of osteoprogenitor cells.[5] The dem- 
onstrated ability of stem cells in adult bone marrow (BM), termed mesenchymal stem cells (MSCs), to differentiate into osteoblasts, chondrocytes, muscle cells, and stromal adipocytes offers an approach for improving the integration of bone grafts to deal with extensive bone loss.[6-8]

For in vitro colonization of allogeneic bone matrix (ABM) by autologous MSCs prior to grafting - a procedure we have termed 'graft personalization' - we studied the in vitro compatibility of a secured inorganic human bone matrix with MSCs from normal adult BM. Different treatments of the scaffold were tested, including the use of human serum (HS) and we studied the adhesion to the bone matrix.

\section{METHODS}

\section{Human normal BM cell source and isolation} Human BM cells were obtained from 17 femoral heads collected during hip arthroplasty. This was carried out according to a protocol approved by the Regional Ethical Committee. All donors (mean age, 63 yearrs) had normal hematopoietic function. Normal BM cells were collected in a syringe containing heparin and transferred to ethylenediaminetetraacetic acid (EDTA)-tubes ( $5 \mathrm{mM}$ ). From each sample, we mechanically dissociated the low-density pre-formed coherent tissue aggregates, which contained about $60 \%$ of the whole BM mesenchymal progenitor cell content.[9] The non-adherent BM mononuclear cells were harvested in 2 gentle rinses and retained for sustaining-hematopoiesis assays. Adherent cells were fed by a weekly change of medium (a-MEM 10\% FCS, $100 \mathrm{U}$ penicillin, $100 \mu \mathrm{g} / \mathrm{mL}$ streptomycin, $2 \mathrm{mM} \mathrm{L-Glutamin).} \mathrm{Mesenchymal} \mathrm{cells} \mathrm{(MCs)} \mathrm{were}$ collected by trypsinization. All the Lin- cells, and some MC, were cryopreserved at $-80^{\circ} \mathrm{C}$ for subsequent use.[10] The number of colony-forming unit-fibroblast-like cells (CFU-F) $[11,12]$ in the cell population was assessed by plating a duplicate fraction at low densities ( 60 and 240 cells $/ \mathrm{cm}^{2}$ ) for 10 days.

\section{ABM}

Allogeneic bone samples were collected from femoral heads, taken from patients undergoing total hip arthroplasty. They were first secured at a tissue bank (Osteobanque, Clermont-Ferrand, France) and then treated with the Osteopure process (Ost developpement, Clermont-Ferrand, France). The steps were: removal of cortical bone, cleaning under pressure, physico-chemical treatment to decrease the lipid content with acetone and ethanol, 2 urea washes and $\gamma$-sterilization.

\section{Assessment of in vitro colonization}

To enhance MCs adherence, ABM were incubated with $20 \mu \mathrm{g} / \mathrm{mL}$ gelatin $(\mathrm{N}=11)$ or $100 \mu \mathrm{g} / \mathrm{mL}$ collagen IV $(\mathrm{N}=5)$ or $20 \mu \mathrm{g} / \mathrm{mL}$ fibronectin $(\mathrm{N}=5)$ or $\mathrm{HS}(\mathrm{N}=7)$ for $2 \mathrm{hr}$. Because of the high variability of trabecular bone-derived matrix in overall surface area, $3 \mathrm{ABM}$ fragments (about $2 \mathrm{~mm}^{3}$ each) per hole were plated in triplicate in 24-hole plates to give a representative series of nine fragments per condition at each time point. Each bone fragment was sowed with the same number of expanded MCs $\left(1.5 \times 10^{4}\right.$ cells $)$ in a standard medium, which was changed twice weekly. To evaluate the kinetics of MC proliferation in each condition, 6 arms with 3 wells, each containing 3 bone fragments, were seeded on the same day (D0). After 1, 2, 3, 4, 6 and 8 weeks, 3 holes (one arm) were sacrificed to collect cells. Cells were harvested after detachment by trypsin/EDTA $0.25 \%$ and counted. For each arm, we evaluated in parallel the kinetics of cell proliferation on equivalently pre-coated plastic holes (gelatin, collagen IV, fibronectin or AB HS) in the absence of $A B M$ as a control in order to estimate the effect of the bone matrix only.

In additional experiments $(\mathrm{N}=6)$, we evaluated the effect of initial MC adherence on ABM colonization. We seeded $M C$ in exactly the same conditions but sacrificed 3 wells $18 \mathrm{hr}$ later and counted adherent cells. In 3 experiments, 3 other holes were maintained in parallel, for 3 weeks then also sacrificed and MC counted to assess the effect of initial adherence on MC proliferation.

\section{Flow cytometry}

We analyzed the size, the granularity of colonizing CD45 CD14 cells and the expression of CD73 antigen to evaluate possible changes in cell characteristics.[13] In all cases, the MCs were first incubated with PBS $/ 5 \% \mathrm{HS}$ for $15 \mathrm{~min}$, then incubated for $30 \mathrm{~min}$ on ice with monoclonal antibodies specific for CD45 (FITC), CD14 (FITC), and CD73-PE (Beckman Coulter, Roissy, France). Cells were washed once in $\mathrm{PBS} / 4 \% \mathrm{FCS}$ and once again in PBS/4\% FCS with $1 \mu \mathrm{g} / \mathrm{mL}$ propidium iodide (PI). Acquisition and analysis of the viable cells (PI-) was performed on an EPICSElite (Coulter Corp., Miami, FL, USA). Gates defining negative cell subsets were 
set using the PE and FITC - conjugated isotype controls.

\section{In vitro hematopoietic supporting function of MCs}

In the standard medium we used, MC usually preserve their capacity to sustain hematopoiesis in vitro. We compared long-term culture in the presence of ABM with culture on routine $M C$ monolayer. Non-adherent cells were depleted of cells expressing CD2, CD3, CD14, CD16, CD19, CD24, CD56, CD66b, and glycophorin A by a negative selection process. This was performed in accordance with the manufacturer's instructions for collecting lineage-negative (Lin) cells, enriched in primitive hematopoietic cells (Stem $\mathrm{Sep}^{\mathrm{TM}}$; StemCell Technologies, Vancouver, Canada). We seeded $5 \times 10^{3} \mathrm{BM} \mathrm{Lin}^{-} \mathrm{CD} 4^{+}$cells per hole $\left(15 \times 10^{3} / \mathrm{arm}\right)$ on personalized $A B M$ in a long-term culture medium that included IMDM, 12.5\% FCS (BioWest, Nuaille, France), 12.5\% horse serum (StemCell Technologies), $2 \mathrm{mM}$ L-glutamine, $10^{-4} \beta$ mercaptoethanol and $10^{-6} \mathrm{M}$ hydrocortisone (Sigma, Saint-Quentin-Fallavier, France). After replacing half the medium once a week over a 6-week period, all the cells from each hole were harvested and plated for the colonyforming cell (CFC) assay, as already described.[9] Monolayers of MC were used as controls and a MS5 cell line as a positive control. We were able to calculate the number of longterm culture initiating cells (LTC-IC) by dividing the total CFC by the average CFC produced from one LTC-IC under the same conditions.[9] In parallel, we assessed the input frequency of LTC-ICs and the number of LTC-ICs maintained for 6 weeks by plating the input and output cells in a limiting dilution assay (LDA) for a further 6 weeks on a MS5 cell line monolayer.

\section{In vitro osteoblastic differentiation}

In other experiments, we replaced standard medium with medium inductive for osteoblastic differentiation. This contained a-MEM $10 \% \mathrm{FCS}, 10^{-2} \mathrm{M} \beta$-glycerol, $5 \times 10^{-3} \mathrm{M}$ ascorbic acid and $10^{-8} \mathrm{M}$ dexamethasone $[14,15]$ and was done at D0, at the end of the exponential phase of proliferation (week 3) and for 3 additional weeks. MCs were then collected after $1 \mathrm{hr}$ incubation with collagenase and assessed for their alkaline phosphatase (ALP) activity on cytospin. MCs were scored by 2 blinded independent observers under microscope in four intensities; 0 , negative; 1 , light beige; 2 , regular moderate brown color; 3 , intense brown; 4 , intense brown nearly black and covering the nucleus. A total ALP score was calculated by adding the score of each MC category (resulting from the percentage of MC) multiplied by the positivity score.

\section{Statistical analysis}

Data were normalized by an arbitrarily defined number of input cells. Results were expressed as means \pm standard deviation. The LDA analysis was performed according to the Poisson statistical model (L-Calc ${ }^{\mathrm{TM}}$; StemCell Technologies). The statistical analysis used the bilateral paired Student's $t$-test with a significant $P$ value less than 0.05 .

\section{RESULTS}

\section{Isolation and in vitro expansion of BM MCs before use}

The number of MCs produced from an average of $5 \mathrm{~mL}$ BM sample is described in Table 1.

Table 1. In vitro expansion of normal bone matrix mesenchymal cells

\begin{tabular}{lcccccc}
\hline & $\begin{array}{c}\text { Absolute no. of } \\
\text { output } \mathrm{MC}\left(\times 10^{6}\right)\end{array}$ & $\begin{array}{c}\text { Frequency of } \\
\text { CFU-F }(\%)\end{array}$ & $\begin{array}{c}\text { Absolute no. of } \\
\text { output CFU-F }\left(\times 10^{6}\right)\end{array}$ & \multicolumn{3}{c}{ Distribution of the size colony (\%) } \\
\cline { 5 - 7 }$P_{0}(\mathrm{~N}=17)$ & $2 \pm 0.9$ & $4 \pm 0.7$ & $0.13 \pm 0.09$ & $51 \pm 10$ & $8 \pm 2$ & $25-50$ \\
$P_{1}(\mathrm{~N}=15)$ & $28.4 \pm 19.8$ & $2.8 \pm 0.6$ & $1.32 \pm 1.00$ & $68 \pm 8$ & $7 \pm 2$ & $25 \pm 8$ \\
$P_{2}(\mathrm{~N}=13)$ & $408 \pm 288$ & $2.3 \pm 0.3$ & $13 \pm 10.6$ & $71 \pm 7$ & $7 \pm 1$ & $22 \pm 6$ \\
$P_{3}(\mathrm{~N}=10)$ & $1167 \pm 730$ & $2.7 \pm 0.6$ & $17 \pm 9$ & $66 \pm 12$ & $7 \pm 3$ & $27 \pm 1$ \\
\hline
\end{tabular}

Adherent bone matrix cells were cultured in standard medium (twice a week exchange) until reaching $80 \%$ of confluence then trypsinated and replated in next passage. A fraction of each cell suspension was plated for CFU-F assay. The progenitors were classified according to the size of the cell colony they produced $(<25,25-50$, and $>50$ cells $)$ at D10. Results are expressed as mean \pm standard error of the mean from indicated number of independent experiments.

MC, mesenchymal cell; CFU-F, colony-forming unit-fibroblast-like cells. 


\section{Proliferation of MCs into bone matrix}

After depositing the in vitro-expanded MCs from $\mathrm{P}_{2}$ or $\mathrm{P}_{3}$ the ABMs were observed at each medium exchange. We noted the first visible bone-adherent cells during the second week, but the bone opacity hampered finding MC. Two weeks later, the cells had proliferated enough to be seen under microscope in bone pores, becoming organized in 3-dimensional (3D) structures after the third week in all coating conditions (Fig. 1). In eleven experiments, we followed the kinetics of the MC proliferation on gelatin pre-

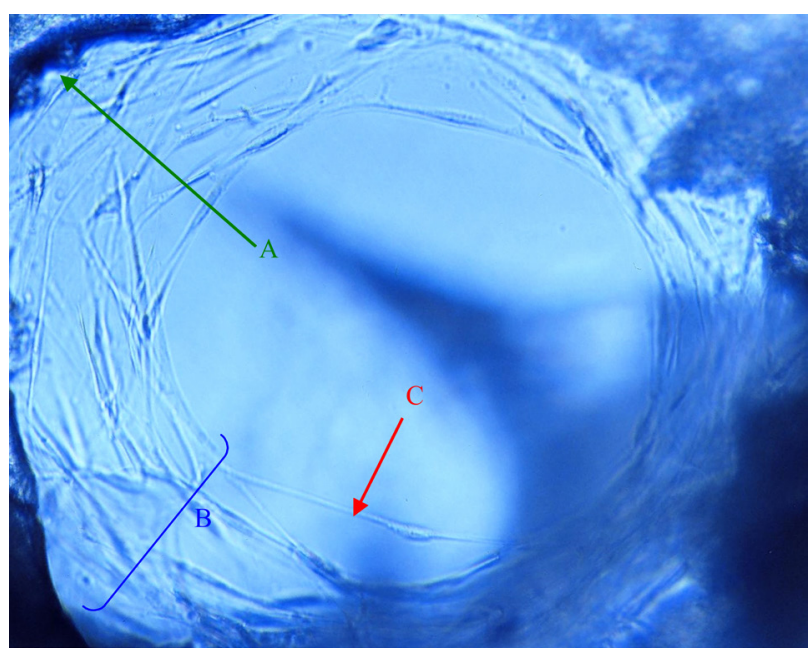

Fig. 1. Appearance of the stalls of the bone matrix after 6 weeks of culture including 3 in osteoblast. The cells line the bone gaps $(A)$ in multilayer (B). We distinguish near the free edge, long cytoplasmic expansions (C). coated-bone matrix, a coating favoring cell adherence. The curve of MC proliferation showed a proliferative phase reaching a maximum at week 4 and finishing with a phase of decrease (Fig, 2A). The normalized numbers of MC collected at W2, W3, and W4 were significantly higher in the presence of bone matrix $(P<0.05)$ resulting in a 2 -fold higher amplification ( $\times 13.3$ vs. 6.6). Then, the 2 curves tended to meet, possibly due to increased senescence in our culture conditions and probably related to the higher cell metabolism indicated by a decreased medium $\mathrm{pH}$. The kinetics of proliferation of MC on bone matrix pre-coated with components with potential for clinical use, i.e. collagen IV $(\mathrm{N}=5)$, fibronectin $(\mathrm{N}=5)$, or decomplemented $\mathrm{AB} \mathrm{HS}(\mathrm{N}=7)$, were followed. In each case, we expressed the result as the number of $M C$ in the presence of $A B M$ divided by that in control (same coating process but without ABM). The proliferation kinetics were roughly similar to those obtained with gelatin coated-ABM (Fig. 2B). AB HS coating seemed to favor their proliferation with a significantly higher number at $W_{2}, W_{3}$, and $W_{4}$, as compared to the control.

\section{Role of initial MC adherence in bone matrix colonization}

To assess the effect of ABM coating on MC adherence, we compared fibronectin and HS coating with PBS $(\mathrm{N}=6)$. After $18 \mathrm{hr}$ of incubation, we observed significantly more adherent cells on HS-coated ABM than on the uncoated ABMs (1.8 fold) or the PBS-incubated (1.7 fold; $P<0.05)$

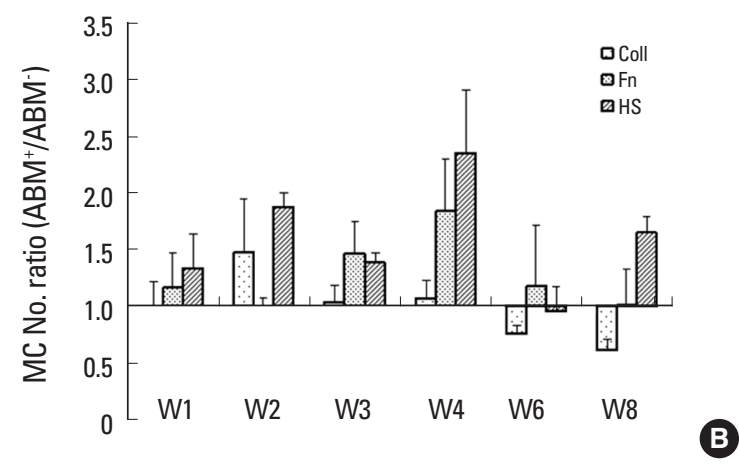

Fig. 2. Kinetics of mesenchymal cell (MC) proliferation. A fixed number of $\mathrm{MC}$ was deposited on allogeneic bone matrix (ABM) or directly in wells (control). At each time point, we sacrificed 3 wells for MC counting. In 11 experiments we analyzed the influence of gelatin-coated ABM on the MC proliferation, comparing gelatin-coated wells without ABM as control (A). In 5 experiments, we tested, in parallel, ABMs coated with collagen IV, fibronectin, or AB human serum. Each coating condition was compared to the corresponding control, i.e., well bottom-coated in same condition. Results are expressed as mean \pm standard error of the mean of ratio calculated as $\mathrm{MC}$ number in presence of $\mathrm{ABM}\left(\mathrm{ABM}^{+}\right)$divided by the number obtained without $\mathrm{ABM}(\mathrm{ABM}-)(\mathrm{B}) .{ }^{*}$ Significance $(P<0.05)$ different with control wells; bilateral paired Student's $t$-test. 
(Fig. 3A). The difference with regard to fibronectin-coated ABMs was at the limit of significance. Furthermore, when we collected $M C$ from the 3 replicates left to proliferate for 3 weeks $(\mathrm{N}=3)$, we found significantly more MC on HS-coated ABM (Fig. 3B) but within a similar range to the initial cell adherence, suggesting that the higher $\mathrm{MC}$ production was related to the larger number of adherent input cells.

\section{Flow cytometry characterization of ABM- colonizing MC}

In the perspective of a clinical application, we checked the characteristics of MC. The CD45 CD14 ${ }^{-} \mathrm{CD} 73^{+}$mononuclear subset contains fresh CFU-F.[16] We analyzed ABMcolonizing $\mathrm{MC}$ by flow cytometry. We observed significantly smaller cells $(P<0.05)$ in the presence of ABMs, whatever
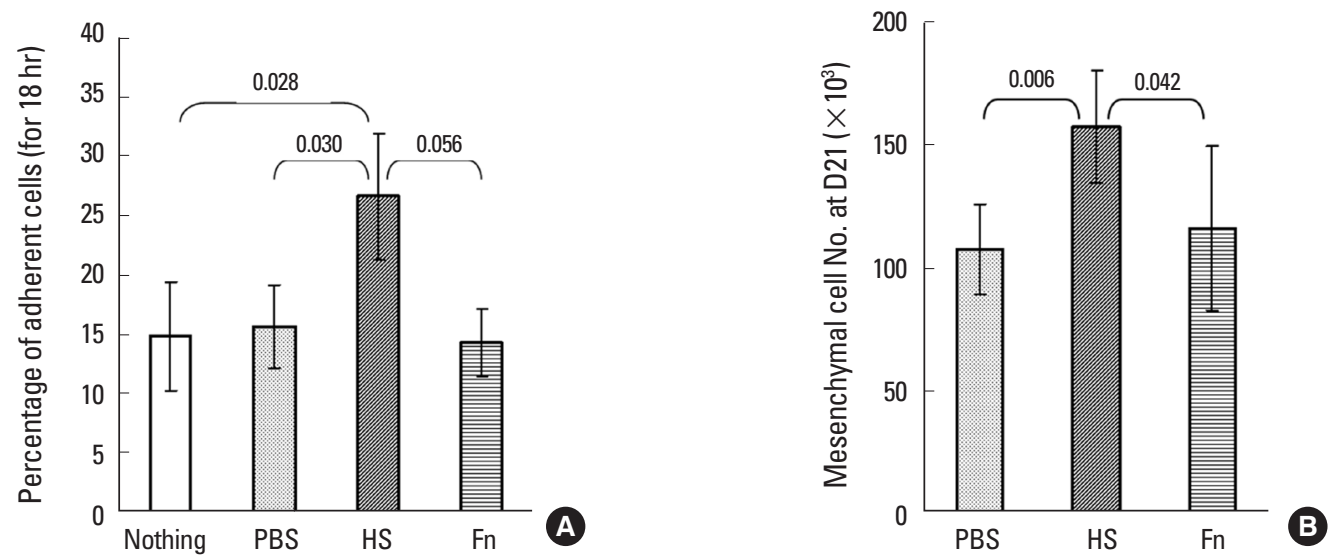

Fig. 3. Distribution of mesenchymal progenitors according to colony size. HS, human serum; Fn, fibronectin
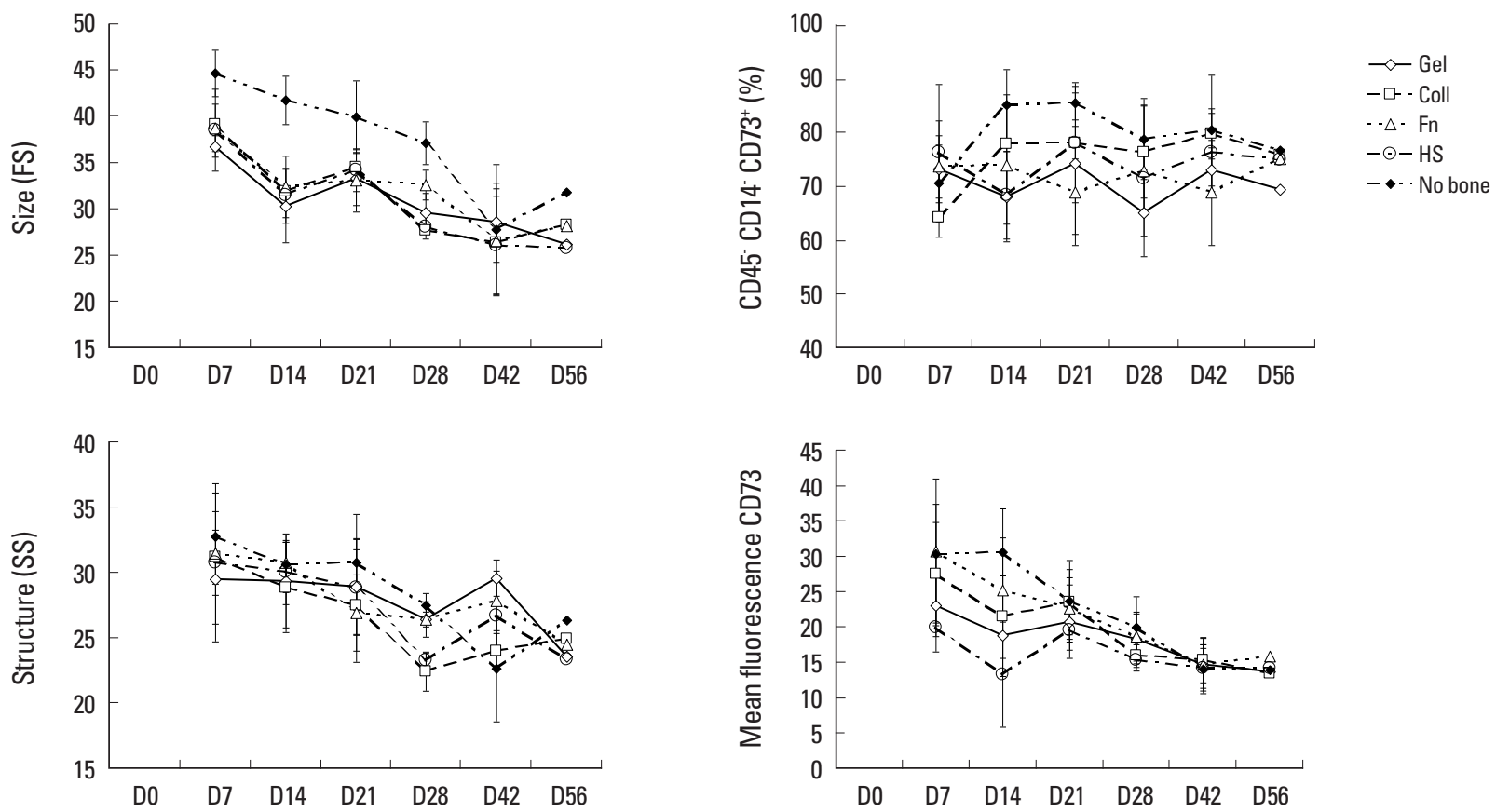

Fig. 4. Influence of initial cell adhesion on mesenchymal cell (MC) proliferation. Allogeneic bone matrix (ABM) triplicates were incubated for 2 hours with human serum (HS), fibronectin (Fn) or phosphate buffered saline as control, then seeded with a fixed number of MC. The 80 hours after the cell deposit into ABM, non-adherent cells were removed and adherent cells collected with trypsin/ethylenediaminetetraacetic acid and counted. The proportion of adherent cells was calculated $(\mathrm{N}=6)$. In 3 experiments, 3 wells were cultured for 3 weeks to evaluate the influence of initial adhesion on MC production. After trypsinization, $\mathrm{MC}$ were counted and the results expressed as mean \pm standard error of the mean; $P$-values are indicated. Gel, gelatin; Coll, collagen. 
the initial conditioning, compared with cells from the wells without bone matrix until the sixth week (Fig. 4). The ABM ${ }^{+}$ curves then joined the ABM- curve. Granularity did not appear to be significantly different, except on D42 in the case of gelatin, and we observed fewer CD45 CD14 ${ }^{-} \mathrm{CD} 73^{+}$cells on $D_{14}$ and $D_{21}$ (fibronectin and $A B H S$ ). The mean fluorescence was lower in the 2 first weeks in the presence of $A B M$ pre-coated with $A B \mathrm{HS}$. We noted that size, structure and mean of fluorescence were inversely correlated with the duration of culture.

\section{Treated bone did not impair osteoblastic differentiation of colonizing MC}

The osteoblastic differentiation of MC was evaluated on $D_{0}$ (input MC) and after 3 weeks of colonizing $A B M$. At these time points, cells were incubated in osteoblastic or standard medium for 3 more weeks, then collected and scored for their ALP activity. The osteoblastic medium induced the production of cells with high ALP activity (stage 3 and 4) from the input cell population, mainly at the expense of cells with no activity (stage $0 ; P<0.03$ ) (Fig. 5A), thus resulting in a 2 -fold increase in total ALP in comparison with a standard medium (Fig. 5B). After 3 weeks growth in bone matrix, the MC was cultured under the same conditions. The distribution pattern of cells according to their ALP activity and the increase in total numbers after osteoblast differentiation was very similar to that observed for input cells, demonstrating that osteoblast potential is conserved after colonization with ABMs (Fig. 5C, D).

Input bone marrow mesenchymal cells
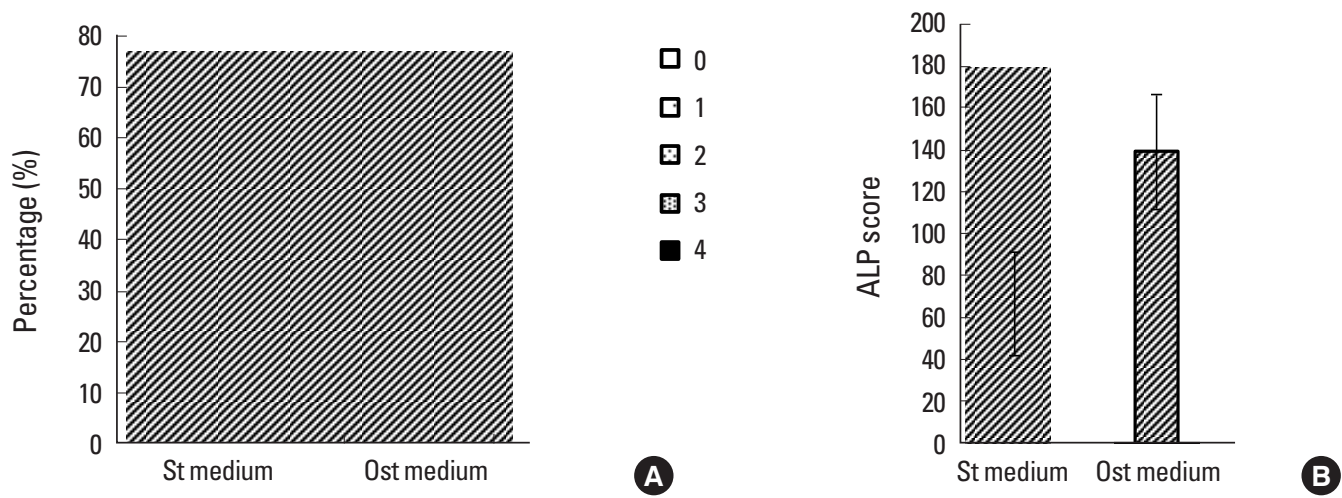

Bone colonizing mesenchymal cells

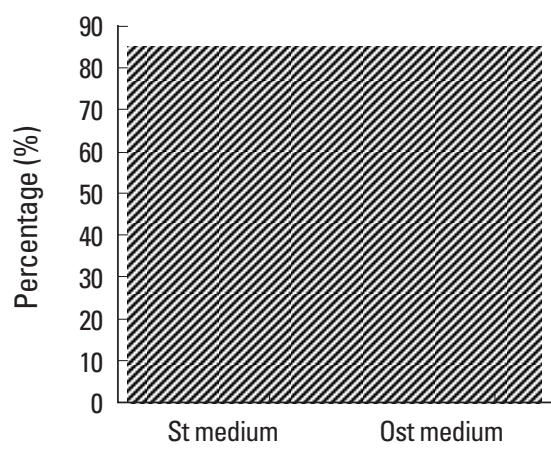

C

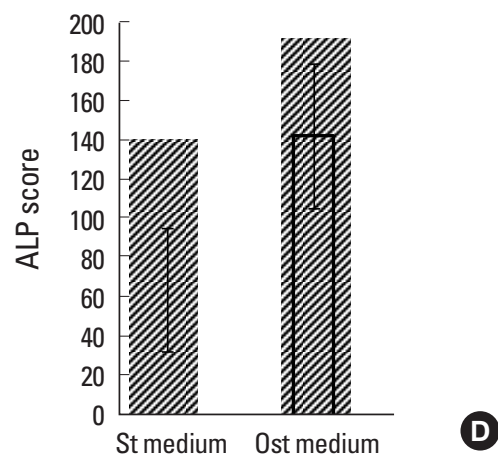

Fig. 5. Analysis of mesenchymal cells (MCs) by flow cytometry. A fraction of MC collected at each time point was analyzed after staining with CD45, CD14, and CD73 mAbs (see materials and methods). The forward (size) and side (structure) scattering characteristics, the percentage of CD45 CD14 CD73, and the mean of fluorescence of the PE-labeled anti-CD73 mAb are shown. Each value corresponds to the mean of 3 independent experiments comparing gelatin-, collagen-, fibronectin-, human serum-coated bone matrix colonizing cells and those cultured in the absence of bone matrix (no bone). ALP, alkaline phosphatase. 


\section{DISCUSSION}

In this study, we evaluated the in vitro ability of normal BM MCs to colonize bone surrogates in a standard medium containing 10\% FCS. Under every experimental condition, $M C$ adhered to ABM surface and proliferated with higher amplitude than on the bottom of the control wells and did so by forming 3D structures similar to those described for other scaffolds.[17] This could be due on the one hand to the improved initial adhesion of mesenchymal progenitors since the most effective $\mathrm{HS}$ coating induced an increase in cell production, and on the other hand, to the surface area of the bone matrix, which by reducing cell density, could favor cell proliferation. $[18,19]$ The effect of HS may be explained by the adsorption of undetermined molecules (apart from fibronectin),[20] facilitating MC adhesion [21] and was probably related to adhesin-dependent signaling events involved in cell survival and growth.[22] Under all conditions, including the control cultures, we observed similar kinetics of CFU-F production, with a trend to decrease with culture time. However, the presence of ABM did not affect CFU-F numbers and, in this aspect, the cell-to-cell contacts in $3 \mathrm{D}$ and cell multilayer did not influence the frequency of progenitors. We noted that bone matrix tended to preserve the initial proliferative potential of CFU-F (colonies $>25$ cells) for 1 to 2 weeks, that could explain the extra numbers of $M C$ from seeded $A B M$ during the first 4 weeks, particularly with $A B$ HS-coated ABMs. The personalization of grafts is a new concept which aims to obtain a graft adapted to each patient. The final step will be to grow the patient's cells in the future transplant that will be implanted, our study allows a preliminary step to this project.

The treated bone did not modify the ability of MC to differentiate towards the osteoblastic Lin since the number of osteoblasts-like-cells was similar before and after colonizing ABM. This observation, associated with the maintenance of a significant proportion of CFU-F, suggests that personalized ABM contained progenitors able to proliferate and differentiate in vivo under the influence of local stimulating factors at the fracture site.[23,24] Primitive MC may differentiate towards different cell types depending upon sitespecific physiological conditions.[25] However, the fact that ALP activity was not increased by the presence of ABM confirmed that the inorganic $A B M$ is not osteoinductive.

Throughout this study, we noted that MC was main- tained in vitro for over 10 weeks. This, and the prolonged phase of cell expansion on bone matrix, suggests that the $M C$ may be able to continue to colonize the bone matrix in vivo. Several teams have been working on the pre-colonization of grafts by undifferentiated MSCs and the approach has been validated in the rabbit,[26] sheep,[27,28] dog,[29] and in man.[30] But these teams used ceramics or coral and not a human bone matrix. However, biomaterial implants are subject to such limitations as inappropriate mechanical properties and poor integration with surrounding tissue.[31] Our approach may appear to go against the current trend by using an allogeneic secured inorganic bone matrix, but the use of this kind of bone surrogate has some evident advantages: (1) its biomechanical properties are very close to those of viable bone [32] offering immediate structural support that may enhance osteogenesis [33]; (2) its porosity and macrostructure should allow graft vascularization; (3) there is no risk associated with xenogeneic graft, comparable to that arising from bovine material, transmission of non-conventional agents (prions) or graft-host incompatibility; (4) their collection is relatively simple. No previous study has tested the biocompatibility of undifferentiated MC and the natural allogeneic inorganic bone matrix and this work is original in this respect. Here, we have validated the first step in the personalization of allogeneic processed-bone matrix.

ABMs coated with autologous serum and colonized by recipient MCs provide an attractive bone bio-graft. Furthermore, we have confirmed that collecting normal BM MCs and performing in vitro expansion in simple medium are feasible procedures and that the expanded MC may be cryopreserved at $-80^{\circ} \mathrm{C}$. This is a cheaper and simpler technique than the preservation in nitrogen that we currently use with hematopoietic cells.[34] However, although we obtained a large number of $\mathrm{MC}$ in vitro, we noted, as have others, that the CFU-F frequency was low $(<5 \%)$ and heterogeneous in proliferative capacity.[7,35,36] Furthermore, we observed an early decrease in the CFU-F proliferative potential through planting out; a fact that urges the use of earlier passages for clinical applications.

\section{DECLARATIONS}

Ethics approval and consent to participate

All procedures performed in studies involving human 
participants were in accordance with the ethical standards of the institution.

\section{Conflict of interest}

Author SB is Zimmer consultant (out of this study). For the remaining authors, no potential conflict of interest relevant to this article was reported.

\section{ORCID}

Roger Erivan https://orcid.org/0000-0003-0923-7672 Guillaume Villatte https://orcid.org/0000-0002-4322-6304 Stéphane Descamps https://orcid.org/0000-0002-9065-7385

\section{REFERENCES}

1. Aaron AD, Wiedel JD. Allograft use in orthopedic surgery. Orthopedics 1994;17:41-8.

2. Erivan R, Villatte $G$, Lecointe $T$, et al. Collection and reconstruction after harvesting donor tissues from the musculoskeletal system: Technique specific to the lower limbs. Orthop Traumatol Surg Res 2018;104:529-32. https://doi. org/10.1016/j.otsr.2018.01.017.

3. Stevenson S. Enhancement of fracture healing with autogenous and allogeneic bone grafts. Clin Orthop Relat Res 1998:S239-46. https://doi.org/10.1097/00003086-1998 10001-00024.

4. Berven S, Tay BK, Kleinstueck FS, et al. Clinical applications of bone graft substitutes in spine surgery: consideration of mineralized and demineralized preparations and growth factor supplementation. Eur Spine J 2001;10 Suppl 2:S16977. https://doi.org/10.1007/s005860100270.

5. Gould SE, Rhee JM, Tay BB, et al. Cellular contribution of bone graft to fusion. J Orthop Res 2000;18:920-7. https:// doi.org/10.1002/jor.1100180611.

6. Berebichez-Fridman R, Montero-Olvera PR. Sources and clinical applications of mesenchymal stem cells: State-ofthe-art review. Sultan Qaboos Univ Med J 2018;18:e26477. https://doi.org/10.18295/squmj.2018.18.03.002.

7. Pittenger MF, Mackay AM, Beck SC, et al. Multilineage potential of adult human mesenchymal stem cells. Science 1999;284:143-7. https://doi.org/10.1126/science.284.5411. 143.

8. Prockop DJ. Marrow stromal cells as stem cells for nonhematopoietic tissues. Science 1997;276:71-4. https://doi.org/ 10.1126/science.276.5309.71.
9. Boiret N, Kanold J, Bons JM, et al. Granulocyte colony-stimulating factor-mobilized peripheral blood CD34+ cells from children contain the same levels of long-term culture-initiating cells producing the same numbers of colony-forming cells as those from adults, but display greater in vitro monocyte/macrophage potential. Br J Haematol 2001;112: 806-13. https://doi.org/10.1046/j.1365-2141.2001.02604.x.

10. Makino S, Harada M, Akashi K, et al. A simplified method for cryopreservation of peripheral blood stem cells at -80 degrees $\mathrm{C}$ without rate-controlled freezing. Bone Marrow Transplant 1991;8:239-44.

11. Castro-Malaspina H, Gay RE, Resnick G, et al. Characterization of human bone marrow fibroblast colony-forming cells (CFU-F) and their progeny. Blood 1980;56:289-301.

12. Friedenstein AJ, Deriglasova UF, Kulagina NN, et al. Precursors for fibroblasts in different populations of hematopoietic cells as detected by the in vitro colony assay method. Exp Hematol 1974;2:83-92.

13. Barry F, Boynton R, Murphy M, et al. The SH-3 and SH-4 antibodies recognize distinct epitopes on CD73 from human mesenchymal stem cells. Biochem Biophys Res Commun 2001;289:519-24. https://doi.org/10.1006/bbrc.2001. 6013.

14. Cheng SL, Yang JW, Rifas L, et al. Differentiation of human bone marrow osteogenic stromal cells in vitro: induction of the osteoblast phenotype by dexamethasone. Endocrinology 1994;134:277-86. https://doi.org/10.1210/endo.134. 1.8275945 .

15. Gronthos S, Graves SE, Ohta S, et al. The STRO-1+ fraction of adult human bone marrow contains the osteogenic precursors. Blood 1994;84:4164-73.

16. Le Blanc K, Ringdén O. Immunobiology of human mesenchymal stem cells and future use in hematopoietic stem cell transplantation. Biol Blood Marrow Transplant 2005; 11:321-34. https://doi.org/10.1016/j.bbmt.2005.01.005.

17. Benayahu D, Kompier R, Shamay A, et al. Mineralization of marrow-stromal osteoblasts MBA-15 on three-dimensional carriers. Calcif Tissue Int 1994;55:120-7. https://doi.org/ 10.1007/bf00297187.

18. Colter DC, Class R, DiGirolamo CM, et al. Rapid expansion of recycling stem cells in cultures of plastic-adherent cells from human bone marrow. Proc Natl Acad Sci U S A 2000; 97:3213-8. https://doi.org/10.1073/pnas.070034097.

19. Colter DC, Sekiya I, Prockop DJ. Identification of a subpopulation of rapidly self-renewing and multipotential adult 


\section{$\mathrm{JBM}$}

stem cells in colonies of human marrow stromal cells. Proc Natl Acad Sci U S A 2001;98:7841-5. https://doi.org/10.1073/ pnas. 141221698.

20. Dennis JE, Haynesworth SE, Young RG, et al. Osteogenesis in marrow-derived mesenchymal cell porous ceramic composites transplanted subcutaneously: effect of fibronectin and laminin on cell retention and rate of osteogenic expression. Cell Transplant 1992;1:23-32. https://doi.org/10.1177/ 096368979200100106.

21. El-Ghannam A, Ducheyne P, Shapiro IM. Effect of serum proteins on osteoblast adhesion to surface-modified bioactive glass and hydroxyapatite. J Orthop Res 1999;17:3405. https://doi.org/10.1002/jor.1100170307.

22. Lee JW, Kim YH, Park KD, et al. Importance of integrin beta1-mediated cell adhesion on biodegradable polymers under serum depletion in mesenchymal stem cells and chondrocytes. Biomaterials 2004;25:1901-9. https://doi.org/ 10.1016/j.biomaterials.2003.08.037.

23. Kloen P, Di Paola M, Borens O, et al. BMP signaling components are expressed in human fracture callus. Bone 2003; 33:362-71. https://doi.org/10.1016/s8756-3282(03)00191-1.

24. Kloen P, Doty SB, Gordon E, et al. Expression and activation of the BMP-signaling components in human fracture nonunions. J Bone Joint Surg Am 2002;84:1909-18. https://doi. org/10.2106/00004623-200211000-00001.

25. Gurevitch O, Kurkalli BG, Prigozhina T, et al. Reconstruction of cartilage, bone, and hematopoietic microenvironment with demineralized bone matrix and bone marrow cells. Stem Cells 2003;21:588-97. https://doi.org/10.1634/ stemcells.21-5-588.

26. Louisia S, Stromboni M, Meunier A, et al. Coral grafting supplemented with bone marrow. J Bone Joint Surg Br 1999; 81:719-24. https://doi.org/10.1302/0301-620x.81b4.9358.

27. Kon E, Muraglia A, Corsi A, et al. Autologous bone marrow stromal cells loaded onto porous hydroxyapatite ceramic accelerate bone repair in critical-size defects of sheep long bones. J Biomed Mater Res 2000;49:328-37. https://doi.org/ 10.1002/(sici)1097-4636(20000305)49:3 <328::aid-jbm5> 3.0.co;2-q.
28. Petite H, Viateau V, Bensaïd W, et al. Tissue-engineered bone regeneration. Nat Biotechnol 2000;18:959-63. https://doi. org/10.1038/79449.

29. Bruder SP, Kraus KH, Goldberg VM, et al. The effect of implants loaded with autologous mesenchymal stem cells on the healing of canine segmental bone defects. J Bone Joint Surg Am 1998;80:985-96. https://doi.org/10.2106/ 00004623-199807000-00007.

30. Quarto R, Mastrogiacomo M, Cancedda R, et al. Repair of large bone defects with the use of autologous bone marrow stromal cells. N Engl J Med 2001;344:385-6. https:// doi.org/10.1056/nejm200102013440516.

31. Perry CR. Bone repair techniques, bone graft, and bone graft substitutes. Clin Orthop Relat Res 1999:71-86. https:// doi.org/10.1097/00003086-199903000-00010.

32. Erivan R, Villatte G, Cueff R, et al. Rehydration improves the ductility of dry bone allografts. Cell Tissue Bank 2017; 18:307-12. https://doi.org/10.1007/s10561-017-9630-9.

33. Vander Griend RA. The effect of internal fixation on the healing of large allografts. J Bone Joint Surg Am 1994;76: 657-63. https://doi.org/10.2106/00004623-19940500000005.

34. Halle P, Tournilhac O, Knopinska-Posluszny W, et al. Uncontrolled-rate freezing and storage at -80 degrees $C$, with only 3.5-percent DMSO in cryoprotective solution for 109 autologous peripheral blood progenitor cell transplantations. Transfusion 2001;41:667-73. https://doi.org/10.1046/ j.1537-2995.2001.41050667.x.

35. Digirolamo CM, Stokes D, Colter D, et al. Propagation and senescence of human marrow stromal cells in culture: a simple colony-forming assay identifies samples with the greatest potential to propagate and differentiate. $\mathrm{Br} J \mathrm{Hae}-$ matol 1999;107:275-81. https://doi.org/10.1046/j.1365-2141. 1999.01715.x.

36. Kuznetsov SA, Krebsbach PH, Satomura K, et al. Singlecolony derived strains of human marrow stromal fibroblasts form bone after transplantation in vivo. J Bone Miner Res 1997;12:1335-47. https://doi.org/10.1359/jbmr.1997. 12.9.1335 
